\title{
After Dolly - ethical limits to the use of biotechnology on farm animals
}

Lassen, Jesper; Gjerris, Mickey; Sandøe, Peter

Published in:

Theriogenology

DOI:

10.1016/j.theriogenology.2005.09.012

Publication date:

2006

Document version

Publisher's PDF, also known as Version of record

Citation for published version (APA):

Lassen, J., Gjerris, M., \& Sandøe, P. (2006). After Dolly - ethical limits to the use of biotechnology on farm animals. Theriogenology, 65(5), 992-1004. https://doi.org/10.1016/j.theriogenology.2005.09.012 


\title{
After Dolly - ethical limits to the use of biotechnology on farm animals ${ }^{1}$
}

\author{
J. Lassen*, M. Gjerris \& P. Sandøe \\ * Corresponding author
}

\begin{abstract}
The cloning of Dolly the sheep gave rise to a widespread call for limits on interference with life. Until recently the main limits were technical: what it is possible to do. Now scientists are faced with ethical limits as well: what it is acceptable to do. In this context we take ethics to involve systematic and rational reflection on moral issues raised in the public sphere. The concerns of the general public are not necessarily valid, but they are the best point of departure if the discussion is to lead to a socially robust framework for setting limits to the use of animal biotechnology. To assess public understanding we examine two sources of data: Eurobarometer surveys from 1991 to 2002 and a qualitative interview study carried out in Denmark in 2000. Based on these sources, we formulate, and then discuss closely, the following concerns: dangers to human health and the environment, animal welfare, animal integrity, and usefulness. In the final part of the article it is proposed that a principle of proportionality should be the foundation for socially robust applications of animal biotechnology. Only in cases where the usefulness of the technology can be said to outweigh countervailing moral concerns, as in biomedical research, will applications of animal biotechnology stand up to scrutiny in the public sphere.
\end{abstract}

Key Words: Cloning, ethics, biotechnology, general public, integrity

\section{Dolly and the public awareness of animal biotechnology}

Dolly was an unusual sheep. She was in a radical sense fatherless. She originated from a cell taken from the udder of her biological mother. This cell was inserted into a sheep ovum from which the nuclear genome had been removed, and it was manipulated so that it fused with the 'egg-mass' or cytoplasm of the ovum to form a embryo. The embryo was then inserted into a foster mother who went through a normal, albeit closely monitored, pregnancy which resulted in the birth of Dolly - the first mammal to be cloned from an adult animal.

\footnotetext{
${ }^{1}$ The reference of the printed version is:

Jesper Lassen, Mickey Gjerris \& Peter Sandøe (2006): After Dolly - Ethical limits to the use of biotechnology on farm animals. Theriogenology, Volume 65, issue 5: 992-1004.

The definitive version is available at

http://www.sciencedirect.com/science? ob=ArticleURL\&_udi=B6TCM-4HDG96R-

$2 \&$ user $=6447644 \&$ coverDate $=03 \% 2 \mathrm{~F} 15 \% 2 \mathrm{~F} 2006 \&$ rdoc $=1 \&$ fmt $=$ high $\&$ orig $=$ search $\&$ origin $=$ search $\&$ sort $=\mathrm{d} \&$ docanchor $=\&$ view $=c \&$ searchStrId $=1475464136 \&$ rerunOrigin $=$ google $\&$ acct $=$ C000034378\&_version $=1 \&$ urlVersi $\underline{\text { on }=0 \& \text { userid }=6447644 \& \mathrm{md} 5=9 \mathrm{~d} 09666 \mathrm{~d} 17 \mathrm{~cd} 80088 \mathrm{~b} 1 \mathrm{a} 1 \mathrm{c} 1754867657 \& \text { searchtype }=\mathrm{a}}$
} 
Her life was quite different from the lives of other sheep in another way too. Few sheep have names, and if they do, very few people generally know their names. Millions of people, on the other hand, know Dolly's name. Her life and death was international news, and today she has become a symbol unifying many aspects of the public concern in the debate about biotechnology. In the main, her fame is not based on admiration and fascination. Rather, it is largely the product of public anxiety, and in particular moral concern. This single Dorset ewe brought to many people's attention the fact that scientists had made a major breakthrough in their attempts to manage and control life. She also gave rise to a widespread call for ethical limits to be established and enforced to human interference with life. Until recently, the main limits of this kind of science were technical in nature. The question was: what is it possible to do? Now, and increasingly, scientists face ethical limits. The question has become: what is it acceptable to do?

This question of acceptability is ethical and can be answered from different points of view. In this paper we will take as our starting point European public perceptions of animal cloning and other applications of biotechnology on farm animal species. In taking this approach we do not assume that the public is always right in matters of ethics. Rather our point is that the problem that faces those who, in a European context, want to be allowed to make use of animal biotechnology is to get on speaking terms with the rest of society. Therefore, by presenting the views of the public within an ethical context it will be possible to make sure that the ethical issues being discussed are relevant from the point of view of a wider public. The upshot of the ethical discussion presented in this paper will be to identify issues that must be dealt with when it comes to regulation and guidelines covering the development and use of animal biotechnology in a European — and probably also a much wider — context.

\section{Biotechnology, animals, ethics and the public}

For the general public animal biotechnology does not exist in a vacuum. It coexists with other applications of biotechnology, primarily within agriculture and the medical area. It therefore makes good sense to discuss, first of all, how animal applications relate to these other uses of biotechnology.

In order to monitor lay perceptions of the new biotechnologies within the EU, the European Commission has carried out regular surveys since 1989 - the most recent being undertaken in 2002. Each of these so-called 'Eurobarometer' surveys consists of simultaneous, identical national surveys of 1.000 inhabitants in each member country. The surveys show that wholesale rejection of biotechnology is not very common among Europeans, since many respondents make balanced judgements in which the pros and cons of the different applications of biotechnology are variably assessed $(1,2,3)$. They also bring out interesting details of lay thought about biotechnology. In each survey, and in connection with several applications, people are asked to consider the usefulness, risks and moral acceptability of biotechnology, and to give an overall assessment. It turns out that, across Europe, and for all applications, moral acceptability outweighs the other parameters when it comes to explaining the overall assessment of the application. Less surprisingly, perhaps, medical applications tend to be viewed as more acceptable than those within the food sector are. Perceived usefulness, risks and moral acceptability all play a role in this latter distinction. Crucially, however, the usefulness of many medical applications is generally recognised, whereas the usefulness of food applications has yet to be demonstrated to the public. 
Table 1: Mean scores in the judgement of to what extent different applications of biotechnology should be encouraged in the 15 EU countries.

\begin{tabular}{|c|c|c|c|}
\hline & \multicolumn{3}{|c|}{$\begin{array}{l}\text { "Should be encouraged" } \\
\text { Mean score in } 15 \mathrm{EU} \text { countries } \\
-2=\quad \text { negative attitude; } \\
+2=\text { positive attitude }\end{array}$} \\
\hline & 2002 a) & 1999 b) & $1996 \mathrm{c})$ \\
\hline $\begin{array}{l}\text { Using genetic testing to detect diseases we might have inherited from our } \\
\text { parents such as cystic fibrosis, mucoviscidosis or thalassaemia }\end{array}$ & 0,69 & 0,67 & 0,91 \\
\hline $\begin{array}{l}\text { Introducing human genes into bacteria to produce medicines or vaccines, } \\
\text { for example to produce insulin for diabetics }\end{array}$ & na & 0,51 & 0,81 \\
\hline $\begin{array}{l}\text { Developing genetically modified bacteria to clean up slicks of oil or } \\
\text { dangerous chemicals }(\mathrm{N})\end{array}$ & na & 0,51 & na \\
\hline $\begin{array}{l}\text { Cloning human cells or tissues to replace a patient's diseased cells that are } \\
\text { not functioning properly, for example, in Parkinson's disease or forms of } \\
\text { diabetes or heart disease (M) }\end{array}$ & 0,49 & 0,33 & na \\
\hline $\begin{array}{l}\text { Using genetically modified organisms to produce enzymes as additives to } \\
\text { soaps and detergents that are less damaging to the environment }(\mathrm{N})\end{array}$ & 0,23 & na & na \\
\hline $\begin{array}{l}\text { Developing genetically modified animals for laboratory research studies, } \\
\text { such as a mouse with genes that cause it to develop cancer }\end{array}$ & na & na & 0,22 \\
\hline $\begin{array}{l}\text { Introducing human genes into animals to produce organs for human } \\
\text { transplants, such as into pigs for human heart transplants }(\mathrm{N})\end{array}$ & 0,13 & na & $-0,22$ \\
\hline $\begin{array}{l}\text { Taking genes from plant species and transferring them into crop plants, to } \\
\text { make them more resistant to insect pests }\end{array}$ & 0,08 & 0,03 & 0,34 \\
\hline $\begin{array}{l}\text { Cloning animals such as sheep to get milk which can be used to make } \\
\text { medicines and vaccines }(\mathrm{N})\end{array}$ & na & $-0,17$ & na \\
\hline $\begin{array}{l}\text { Use modern biotechnology in the production of foods, for example to make } \\
\text { them higher in protein, keep longer or improve the taste }\end{array}$ & $-0,26$ & $-0,31$ & $-0,11$ \\
\hline
\end{tabular}

REFERENCES: a) European Commission. Eurobarometer 58.0, Services of general interest. European Commission, DG Press and Communication. 2002; b) INRA (Europe) (2000): Eurobarometre 52.1. Les Europeens et la biotechnologie. 15. mars 2000. c) Durant, J., Bauer, M.W. \& Gaskell, G. (eds.) (1998): Biotechnology in the public sphere - a European sourcebook. Science Museum. London. NOTE: "na" in the table indicates that this question was not included in this Eurobarometer 
As Table 1 shows, the food-medical divide is not alone in separating negatively assessed applications from positively assessed ones. In the 1996 survey applications of biotechnology involving animals have, it seems, a low level of support similar to applications within the food area: the least supported application of all is xenotransplantation, and the use of research animals enjoys almost as low a level of support as the production of GM foods. The 1999 survey displays similar patterns. The one animal application (i.e. "cloning of animals such as sheep to get milk which can be used to make medicines and vaccines") emerged as having almost as low a level of support as the least supported application, GM foods (4). In the 2002 Eurobarometer survey (in which the sole animal application is xenotransplantation), although the animal technology is used for clearly medical purposes, it is given almost as low a level of support as the use of biotechnology in the food-sector. It should be mentioned however that the surveys from 1999-2002 show limited, but steadily increasing, support for the use of biotechnology in general and also for research into, and applications of, xenotransplantation.

All three of the applications of animal biotechnology in Table 1 fall within the medical sphere, and yet they command a relatively low level of support. A possible explanation for this is the simple fact that they involve animals. It is also possible, however, that the specific applications in question - cloning, research animals and xenotransplantation - in themselves evoke a negative reaction. Thus animal cloning is associated in some people's minds with the development of human cloning - and the debate as a consequence of this influenced by the critical debate about human cloning. The xenotransplantation of pig hearts into humans is likely to cause unrest because an important barrier between man and animals is thereby breached and blurred. In addition, for many people the use of animals in research calls up an image of cruelty to animals.

Some of the follow-up questions in the 1999 Eurobarometer throw more light on animal cloning. Responses to these questions partly explain the rejection of this particular application. Participants were asked to assess 12 statements about cloning on a five point scale, where $5=$ 'strongly agree' and $1=$ 'strongly disagree'. The two most strongly supported statements concerned the perceived unnaturalness of cloning. Thus the average score of the statement "even if animal cloning has advantages, it is basically against nature" and "animal cloning threatens the natural order of things" scored 4.24 and 4.12 respectively. Similarly most agreed (average score 3.85) that animal cloning was simply not necessary, and most disagreed with the statements that animal cloning presents no danger to future generations (average 2.19) and that the risks involved in animal cloning are acceptable (average 2,28) (4)).

The lack of support for animal cloning therefore seems to reflect the fact that ordinary people believe it to be both unnatural, lacking in real usefulness and a genuine risk to humankind. Other medical applications are perceived to be much more useful and much less risky, even though they are also thought of as unnatural.

\section{Scepticism does not merely reflect lack of knowledge}

It might be supposed that the pronounced public scepticism about forms of biotechnology such as cloning and other animal biotechnologies reflects a low level of understanding of biotechnology among lay observers. According to this so-called 'knowledge deficit' or 'knowledge gap' model, inadequate knowledge leads the public to draw moral conclusions about practices within science that are ill informed. And since the problem is knowledge, the cure is to feed information into the public sphere more effectively — to educate people. Once this is done, public acceptance will follow. 
Surveys such as the Eurobarometer have seriously challenged this viewpoint by showing that the question of acceptance or rejection is much more complex than advocates of the deficit model suppose. Eurobarometer surveys include a 'knowledge quiz' in which respondents are asked a series of factual questions about biotechnology. This quiz enables the relationship between optimism about biotechnology and level of knowledge to be examined. The examination, however, reveals that optimism and positive expectations have failed to increase with growing knowledge. In fact, it was found in 1997 that, despite a moderate increase in overall knowledge of the subject matter, optimism about biotechnology had declined in Europe (5). As they acquire more information, people are better able to form an opinion for or against biotechnology - that is, there is a decrease in the number of 'don't knows'. However, pace the deficit model, they do not acquire a more positive attitude to biotechnology. In particular, there is at best a poor correlation between knowledge and support of individual applications.

The knowledge deficit model has also been challenged at the national level. In Denmark, for example, considerable resources were invested in public information, education and debate about biotechnology in the 1980s. Following this, Danes were among those scoring highest in the Eurobarometer knowledge quiz $(1,4)$. Nevertheless, the surveys in which Danish participants displayed their knowledge also show that Danes are among the most critical of biotechnology — which, obviously, is clear evidence against the hypothesis that there is a causal link between knowledge and acceptance.

\section{Animals, biotechnology and the public: moving beyond the general picture}

Apart from the indications given by the follow-up questions about cloning, the Eurobarometer does not offer any detailed explanation of the motives and reasoning lying behind critical attitudes to the mix of animals and biotechnology. Thus to add more detail to the picture painted by the Eurobarometer, a series of seven focus group interviews were carried out in Denmark in 2000. Each focus group involved between four and seven participants. Since the aim of the interviews was to explore the arguments underlying the results of surveys like the Eurobarometer, the participants were sampled for their ability to engage with arguments present in the public sphere, rather than cover all social and demographic categories. The interviews followed an interview guide, ensuring on the one hand that the discussion was kept within the frame of the investigation and included different applications and technologies as well as concerns and expectations. On the other hand, the interview guide left room for the participants to explore the field in their discussions without too strong interference from the moderator. Subsequently the interviews were transcribed, coded into themes and within each theme arguments were identified, analysed and generalised.

In the course of these interviews both food and non-food applications of biotechnology were examined. In both cases, a number of animal applications were reviewed.

Generally the interviews reproduced the picture generated by the Eurobarometer surveys - i.e. confirmed that food applications are assessed much more negatively than non-food applications, and that medical applications are assessed most positively. To many, indeed, the border between food and medical applications virtually constituted a boundary between the unacceptable and the acceptable, although in no case did an interviewee approve of an offer of carte blanche to scientists working in biomedicine. An overview of different categories of arguments for and against animal biotechnology appearing in the interviews is presented in figure 1. 


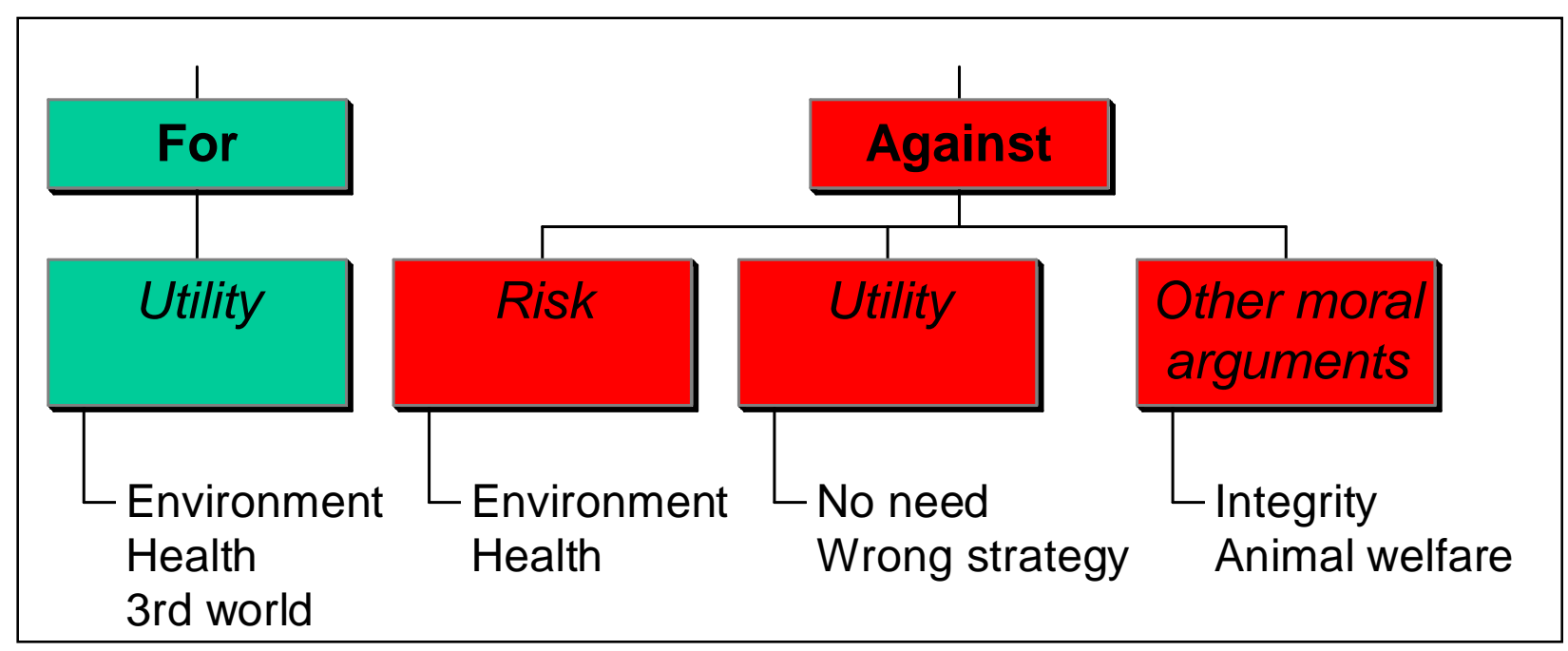

Figure 1: Overview of arguments for and against animal biotechnology offered by participants in seven focus group interviews in Denmark in 2000.

\subsection{Risks}

The focus group discussions revealed that people are concerned about risks to the environment and human health. It is mainly applications within agriculture and food production that give rise to images of risk, and that applications of biotechnology involving animals, including farm animal species, within biomedical research play a remarkably insignificant role in people's perception of risk.

Although a general fear of eating GM foods was not displayed, health risks were an important theme in the food discussions. Concerns about eating genetically manipulated foods related, not to dangers of the here and now, but to long-term risks. Health risks attaching to the consumption of GM meat were only mentioned occasionally, but it must be assumed that general unease about GM food will extend to products originating from genetically modified farm animals. Also incorporated in this unease is a concern that at present 'we' lack sufficient knowledge to make predictions. The 'we' here, as elsewhere, seems to refer to the scientific community and health experts. It records a perception of scientific uncertainty. Such arguments are fortified with experiences drawn from other contested issues, such as the issue of BSE. During the period of the interviews, and following the discovery of an infected cow in Denmark, BSE was widely discussed in Denmark. This gave rise to a fear that scientists are unable to control the consequences of what they are doing.

As regards risks to human health, animal biotechnology is viewed as being on par with applications of biotechnology to plants and microorganisms. This contrasts with the attitude to environmental risks, where some argue that modified animals pose less of a problem. GM animals can be caught and slaughtered if necessary and thus there is less reason to worry about potential problems caused by any uncontrolled spread of 'unwanted genes'. These arguments claim that since animals are larger and slower, they are also easier to control. 
Occasionally, arguments about risk are supported by remarks about the perceived unnaturalness of the new biotechnologies. In such arguments - which are usually expressed in general terms and relate to genetic modification as such — the idea is that, by manipulating animals, we challenge the natural or God-given order of things and thus bypass certain (not always specified) safety mechanisms that are inherent in nature. These safety mechanisms are often associated with barriers between species and the inherent slowness of traditional breeding and propagation techniques.

Other qualitative interviews have demonstrated that, in contrast with widespread concern about the health risks of xenotransplantation within the scientific community, the technology is only discussed in terms of risk by lay people to a limited extent (7). Similarly, these interviews demonstrate that perception of risk plays no direct role in negative lay perceptions of the use genetically modified research animals.

Finally, it should be mentioned that the biotechnologies that are now being used on animals are often seen as an augury of what later will be used on humans. The debate around the cloning of Dolly is a classic example of this. It very quickly turned from the ethical problems arising form the cloning of animals to the problems arising from application of the same technology to humans. It is noteworthy that most western countries very quickly legislated against the cloning of human cells where as only a few countries to date have introduced legislation concerning the use of cloning on animals. The implication seems to be that, to many observers, the use of biotechnology on animals is the starting point of a 'slippery slope' down which one inevitably slides towards use of the same technologies on humans.

\subsection{Animal welfare}

Animal welfare, and especially the welfare of domestic animals, has been a major issue in Denmark over recent decades. Strikingly, however, while the welfare of both domestic and research animals has been widely discussed, welfare problems for genetically modified or cloned animals has largely been ignored in the public debate. This disparity is expressed in the interviews when discussion touches on domestic animals: the issue of animal welfare is taken up spontaneously in two of the interviews, and in both cases the interviewees referred to animal welfare problems in cows engineered to produce more milk - doubtless, a reflection of the fact that this issue has been the most prominent in the public debate about animal welfare issues and biotechnology.

Although the suffering of genetically modified research animals has so far not become a public issue, it does come up in the focus groups. This might be because animal suffering is one of the issues - even the major issue - raised quite generally by the use of animals for research. Here, as in debates over transgenic research animals, it should be noted that it is often hard to separate situations in which research animals are generally disapproved of and situations in which a negative reaction is evoked by a special factor, such as the fact that the animals are transgenic.

\subsection{Other moral arguments}

Another group of concerns (closely related to concerns about animal welfare) has to do with the place of animals in the hierarchy of nature. Thus, some interviewees implied that arguments capable of justifying the 
application of biotechnology to higher organisms would need to be better than those required where microorganisms and plants are at issue.

Typically, in these classifications, the more like us the animals are, the harder it becomes to justify applications of biotechnology. Fish are not as important as calves, for example, and primates are preeminent. The idea of xenotransplantation provokes a particularly negative reaction (7), and some interviewees cannot imagine walking around with the organs of another animal. This feeling tends to be stronger when the organ is a heart and the donor is a pig - perhaps because pigs have traditionally been thought to represent the very opposite of human cleanliness and sophistication.

These concerns often seem less palpable than concerns about risks and animal welfare, but nonetheless they play an important role. Often they are expressed in the terms of borders and limits. They indicate that to some people there are as it were freestanding limits to the degree of control that humans can ethically exercise over other living beings. Concepts such as integrity and dignity are often evoked to describe these limits. There is a tendency in the academic literature to write off such limits as irrational and/or religious, but lack of conceptual clarity should not lead one to dismiss them too quickly. The idea of nature having some sort of integrity seems to be rooted in very common everyday experience and expresses a view of nature that goes beyond the purely scientific one. The concept is certainly complex, ambiguous and in need of further examination. However, it seems to be important in our understanding of public perceptions of biotechnology (6).

\subsection{Usefulness}

In public debate about biotechnology, the predominant tone is often negative - the question is often whether this or that application should be rejected. A less negative attitude comes into the foreground when people are asked to consider the usefulness of biotechnologies. However, the concept of usefulness is complex and contested.

Three interpretations of usefulness can be identified in the biotechnology debate. Each was reflected at some point in the interviews. Some observers - primarily representatives of the biotech industry and others with vested interests in biotechnology - defend an economic usefulness argument according to which biotechnology is useful in technical and financial terms. Many of the participants in the interviews did not share this notion. Indeed some stated that making money is, on its own, not a sufficient argument for such controversial technologies.

The societal usefulness argument is in keeping with this latter attitude. Commonly, it is either put directly or gestured at in the interviews. The main idea here is that biotechnology is useful, and to that extent acceptable, when it serves societal needs that amount to more than mere economic gain. The final kind of usefulness concerns usefulness to oneself or one's close relatives. This (as we might call it) self-interested usefulness often generates serious dilemmas in which abstract, objective assessments clash with highly contextualised, subjective assessments involving the health or life and death of oneself or a close relative.

In general, societal usefulness relates primarily to the avoidance of risk, the management or elimination of disease, and the alleviation of third-world poverty. Where domesticated animals are concerned, the transgenic pig with reduced fat is sometimes put forward as an example of a useful application that addresses the recognised health problem of obesity and thus introduces a health benefit to consumers. Those advancing 
this argument seldom do so with reference to themselves. They focus instead on obesity as a societal problem.

Others, however, argue that functional foods in general are the wrong strategy for solving problems connected with the composition of a person's diet. With both the medical sphere and domesticated animals, it is often argued that biotechnology is the wrong way to attain laudable goals. Alternative strategies should be pursued or examined.

In the medical sphere, debates about animals primarily concerned their use in research. Often, these debates involved a dilemma between societal or self-interested usefulness, on the one hand, and general unease about the use of biotechnology and animals, on the other. Like the medical applications of biotechnology to which they lead, research animals were looked upon positively by many interviewees, because their use may help us to relieve the pain and suffering of the sick. This kind of argument, however, is often presented with a disclaimer where it is stressed that, however useful they are, research animals are still problematic.

As mentioned above, it is quite commonly thought that, although transgenic research animals are unacceptable, sufficient benefits to humankind can justify them. A number of arguments against transgenic research animals were presented in which the individual (as a citizen) tried to weigh the pros and cons for society. However, the individuals who put these arguments forward often confessed that, when they had to assess biotechnological applications from a strictly individual point of view, thinking of themselves as potential beneficiaries of the technology they had rejected, they were inclined to adopt a more lenient attitude.

\section{Ethical limits to the use of biotechnology on animals?}

In this article we have tried to show what kinds of concern the use of biotechnology on farm animals evokes in Europeans in connection with farm animals both as species and as production units in the agricultural sector. These concerns can, roughly speaking, be said to give a list of the ethical questions that a society such as Denmark needs to discuss when considering the ethical aspects of biotechnology and establishing a framework for the use of it - at least, if the discussion is to be informed by ethical values that are common among lay people.

There are two main reasons why this approach is desirable. First, the notion that legislation and the regulation of ethically sensitive issues ought to be based on thorough public debate and consensus seeking policies that are sensitive to the ethical questions raised is in keeping with the democratic tradition of Western Europe. Second, it seems obvious that the lesson to be learned from the debate over GM-crops and subsequent consumer reactions in Western Europe is that it is a prerequisite of successful implementation of biotechnology in a society like Denmark is that the ethical doubts of the public are taken seriously when the technology is introduced.

It would be premature to say that a thorough public debate on the use of biotechnology on farm animals has taken place in Denmark or any other western country. Nevertheless, if we take the ethical questions and worries described in this article as a rough guide to the ethical considerations that will emerge from such a debate, a framework for the use of the technology can be drawn. 
It should be noted at this point that establishing the framework for applications of biotechnology on farm animals constitutes only the first step in a very complex process of regulation and legislation. In this article however, we concentrate on the general framework, since worthwhile discussion of the regulatory and legislative process would be a substantial topic in its own right. One area of biotechnology that is particularly interesting from a legal perspective right now is cloning of farm animals.

The technology of cloning is still in the early stage, which is clearly seen by the low success rates (8). Nonetheless, there are areas where cloned animals even with today's low success rates are seen as an economically viable. Both within biomedical research and production as well as within certain aspects of food production the clones are almost ready to enter the market place (9). This development has stressed the need for a public debate about how and if the cloning of farm animals should be regulated,

Today the area of cloned animals is typically regulated indirectly through existing legislation on animal welfare both on a national and international level. A Danish review examined existing legislation in more than 10 countries (including US, Australia, Japan, UK and Germany) in 2003 and found that all countries regulated the cloning of animals along the lines of research animals (10).

However, it may be necessary to regulate both the use of the technology and the products created by it in order to protect consumers, manage environmental risks and protect the animals from unethical treatment. A number of studies assessing such risks have already been published (11), and there is little doubt that these and future studies will play a role in the regulatory discussion. Nevertheless, as shown above there exist other concerns regarding cloned animals than the mere physical risks they or products derived from them might constitute. Moreover, with the cloned animals leaving the labs and showing up in the supermarket so to speak these concerns will become even more visible in the public debate and affect the legislation process.

Returning to the framework for the use of the technology, it is clear that it has to accommodate the real differences between public and scientific conceptions of the risks to human health and to the environment. These differences can be found in many areas of the debate on biotechnology (12). Public attitudes to scientific uncertainty, the lack of lay trust in experts, and public distrust of suspiciously firm reassurances about safety, all need to be addressed.

Second, it is necessary to take the question of animal welfare very seriously. Although it has not yet figured as a predominant subject specifically in the discussion about the use of biotechnology on farm animals, there can be no doubt that welfare plays an important and ever increasing role in the general discussion about farm animal production.

Third, moral concerns about things other than threats to human, environmental and animal welfare have to be respected. These concerns can be about social justice, or who will benefit from the technology, about the relationship between expert and public influence on legislation and regulation, and about the consequences of the technology for the understanding of the relationship between man and nature. However, in this article we limit ourselves to a short description of the concerns about biotechnology's possible violation of the integrity of animals. This concern differs from the concerns about risk and welfare mentioned above in that violation of integrity cannot be sustained by empirical evidence in the same way as, for example, environmental risks or welfare problems. However, it is still possible to illustrate what is at stake. 
An example many people react to is that of blind hens. A Canadian scientist involved in poultry breeding bred a blind egg-laying hen. This hen according to the researcher would help to reduce the welfare problems of free-range chickens, for these birds painfully harm one another by pecking, and sometimes even cannibalising, weaker members of the flock (13). The blindness was not inflicted on living chickens, but something they were born with. From a welfare perspective they would be better off than their seeing peers. Still the notion of deliberately breeding blind hens to solve production problems in the agricultural sector stirs strong emotions and resentment in the general public. Something just seems to be wrong when you deliberately create an animal with less potential than a normal animal of the kind. This is not the place to discuss the many different ways that the idea of blinding hens to improve their welfare can be defended or attacked. Suffice it to say that it is obvious, from the data presented here, that for many people there may be something inherently unethical about using biotechnology to make significant changes in the nature of an animal, whether it hurts the animal or not.

Finally, a key notion in discussions of the ethical acceptability of animal biotechnology is that of utility. This calls for a balancing of the potential ethically good outcomes of the use of biotechnology on farm animals and the ethical wrongs that this use also entails. This can be clearly seen in the relatively sharp distinction that was found between medical and food-orientated uses of the technology. In the first case, the good aspects are often seen as outweighing the bad, whereas the opposite is true in the second case. If the goal is deemed important (or ethically desirable) enough, the evil it entails is accepted as a sort of necessary evil. This weighing of the ethical scales is of course a complex affair that depends upon both the specific use of the biotechnology in question and the person who is performing it. Nevertheless, at the societal level, it seems that, in general, the use of biotechnology on farm animals is something that needs to be argued rather than the other way around: the burden of proof lies with those who advocate the technologies.

To sum up, it seems that a socially robust application of animal biotechnology must limit uses where problems with animal welfare and animal integrity are likely to occur to technologies which are of vital importance, e.g. in biomedical research. In farm animal breeding serious limits ought to be placed on the use of biotechnology. A principle of proportionality, where each application of biotechnology is subjected to scientific and ethical discussion before it is either endorsed or rejected, seems desirable - both ethically and, pragmatically, to ensure that the technology will enjoy broad acceptance among the general public. It should be mentioned that a governmentally appointed committee has in fact suggested this principle as a governing principle in guidelines for applications of biotechnology to animals in Denmark (10).

This way of interpreting the concerns identified in this article and establishing a framework for the application of the technology is perhaps more limiting than most scientists working within the field would like; they may have hoped for more room for manoeuvre. However, if we look at the attitudes of the general public, it seems that any aspiration to deploy very broad applications brings with it a risk that the general public will turn down all uses of the technology — as we saw in the GM-food debate in Europe in the 1990s. The principle of proportionality might rule out several possible applications of biotechnology to farm animals, but it ensures that those left will also be acceptable to the general public. From both a scientific and societal perspective, this is to be preferred. 


\section{Conclusion}

The European public is worried about animal cloning and other forms of animal biotechnology. However, contrary to a widespread belief in the scientific community, this worry cannot simply be explained in terms of a lack or distortion of factual information. To create a socially robust framework for discussion of the ethical limits concerning the use of biotechnology on animals, we believe that one should take these worries as the point of departure. It is not that they should be uncritically surrendered to. They have to be thoroughly discussed. However, to do that we shall need a real understanding of them. The key items on this agenda concern risk, animal welfare, usefulness and several other moral concepts; but in connection with each of these items the public and the scientists may well conceive of the problems differently. Thus, lay people typically view risks in a broader and longer-term perspective than scientists. They also believe that if usefulness is to serve as a positive argument, it must involve more than mere commercial success. It follows that, if European scientists want to be able to use animal biotechnology in their research with public support, they must broaden their conception of what matters beyond scientifically measurable risk; and they must operate with a more demanding notion of usefulness so that the mere possibility of making a profit is not enough to justify animal biotechnology. We suggest that a principle of proportionality should form the basis of ethical evaluation of uses of biotechnology on farm animals. This basically means that any such use must be justified by arguing why it is necessary, in each specific case, to transgress the ethical borders that the concepts of risk, animal welfare and integrity impose. By limiting uses of biotechnology in this way, we foresee that many of the controversies surrounding other uses of biotechnology, such as GM crops, will be avoided.

\section{Acknowledgements}

The authors want to thank Novo Nordisk A/S and the Danish Ministry for Food, Agriculture and Fisheries for providing financial support for the research on which this paper is based. Thanks are also due to Paul A. Robinson for editorial assistance.

\section{References}

(1) Durant J, Bauer MW, Gaskell G (EDS.). Biotechnology in the public sphere - a European sourcebook. Science Museum. 1998.

(2) Gaskell G, Bauer MW (EDS.). Biotechnology 1996-2000 - the years of controversy. Science Museum. 2001.

(3) Gaskell G, Allum N, Stares S. Europeans and Biotechnology in 2002. Eurobarometer 58.0. (2. ed. March $21^{\text {st }}$ 2003). (http://europa.eu.int/comm/public opinion/archives/eb/ebs 177 en.pdf).

(4) INRA (Europe) - ECOSA. Eurobarometre 52.1. Les Europeens et la biotechnologie. 15. mars 2000. (http://europa.eu.int/comm/public_opinion/archives/ebs/ebs_134_fr.pdf)

(5) Wagner W, Torgerson H, Einsiedel E, et al. Biotechnology and the European Public Concerted Action group. Europe ambivalent on biotechnology. Nature. 1997; (387)6636: 845-847. 
(6) Cooper, DE. Intervention, humility and animal integrity. In: Animal Biotechnology and Ethics, Holland A, Johnson A (EDS.), Chapman \& Hall, 1998, pp. 145-155.

(7) Dahl K, Sandøe P, Johnsen, PF, Lassen J, Hansen AK. Outline of a risk assessment: the welfare of future xeno-donor pigs. Animal Welfare 2003; 12:219-237.

(8) Paterson, L. Somatic cell nuclear transfer (cloning) efficiency. Roslin Institute. 2002. (www.roslin.ac.uk/public/webtablesGR.pdf)

(9) Danish Centre for Bioethics and Risk Assessment. The Science and Technology of Farm Animal Cloning: A review of the state of the art of the science, the technology, the problems and the possibilities. Report from the project Cloning in Public, A specific support action within the 6th framework programme, priority 5: Food quality and safety. Available at www.bioethics.kvl.dk/cloninginpublic.htm

(10) Ministeriet for Videnskab, Teknologi og udvikling. Genmodificerede og klonede dyr. [Genetically modified and cloned animals (Report in Danish)]. København. 2003.

(11) Cloning and Stem Cells, 2004. 6:2 (2004). Special issue reporting from the symposium "The Assessment of Food Quality from Cloned Animals.

(12) Hansen J, Holm L, Frewer L, Robinson P, Sandøe P. Beyond the knowledge deficit. Recent research into lay and expert attitudes to food risks. Appetite 2003; 41(2):111-121

(13) Ali A, Cheng, KM. Early egg production in genetically blind ( $\mathrm{rc} / \mathrm{rc}$ ) chickens in comparison with sighted (Rc+/rc) controls. Poult. Sci. 1985; 64(5):789-94. 